\title{
Determining the rate of follow-up after hospital emergency department visits for dental conditions
}

This article was published in the following Dove Press journal:

Clinical, Cosmetic and Investigational Dentistry

30 March 2016

Number of times this article has been viewed

\author{
Beau Meyer ${ }^{1,2}$ \\ Eric Adkins ${ }^{3,4}$ \\ Nathan M Finnerty ${ }^{4}$ \\ Fonda G Robinson ${ }^{5}$ \\ 'Division of Pediatric Dentistry, \\ College of Dentistry, The Ohio \\ State University, Columbus, $\mathrm{OH}$, \\ ${ }^{2}$ Department of Pediatric Dentistry, \\ School of Dentistry, University \\ of North Carolina at Chapel Hill, \\ Chapel Hill, NC, ${ }^{3}$ The Ohio State \\ University Wexner Medical Center \\ Emergency Department, ${ }^{4}$ Department \\ of Emergency Medicine, College of \\ Medicine, ${ }^{5} \mathrm{Clinic}$ Administration and \\ Patient Care, College of Dentistry, \\ The Ohio State University, Columbus, \\ $\mathrm{OH}$, USA
}

Background: Emergency department (ED) visits for dental reasons continue to impact EDs nationwide. This investigation determined the rate of follow-up in an emergency dental clinic (EDC) after hospital ED visits for nontraumatic dental conditions.

Methods: This prospective investigation reports the number of patients who presented to an ED for nontraumatic dental conditions and the rate of follow-up at an EDC. Upon ED discharge, patients were provided instructions to follow-up for low-cost care at the EDC. Telephone contact was attempted following failed referrals. Descriptive statistics were reported for comparing referral sources and demographic trends.

Results: Two hundred and forty-seven referrals were made and $31 \%$ followed up for definitive treatment at the EDC. More referrals were made on weekends than on weekdays. Failed referrals were unreachable by telephone in $75 \%$ of cases. Tooth extraction was the most common treatment rendered in the EDC. Of the ED patients who accessed EDC care, 14\% became comprehensive patients in the EDC's regular dental clinic.

Conclusion: Less than one-third of ED referrals to the EDC followed up for definitive care when provided an opportunity to do so, and $75 \%$ of referrals were unreachable by telephone in the week following the ED dental visit.

Keywords: emergencies, dental health services, health services accessibility, access to care, dental emergency treatment

\section{Introduction}

An increasing number of individuals in the US have been utilizing hospital emergency departments (EDs) for their emergent and urgent dental care throughout the past 10 years. ${ }^{1-3}$ When compared to ED visits for nondental reasons, a disproportionate number of dental patients come from low-income families and few have dental insurance, ${ }^{1-5}$ the same groups of people also bear a greater burden of dental disease. ${ }^{6}$

ED dental visits rarely result in definitive care, with patients frequently receiving an antibiotic and/or pain medication. ${ }^{7}$ When nondefinitive care is provided, patients often return to the ED with the same complaint, making two to eleven additional ED visits. ${ }^{8}$ Additionally, dental care delivered in EDs is not cost-effective, and actually costs substantially more than what would be provided in a dental clinic, averaging nearly $\$ 750$ per ED dental patient in $2012 .^{9}$

An increasing number of working age adults are being covered by Medicaid, which variably offers adult dental benefits and often lacks coverage for basic dental services. ${ }^{10}$ The reimbursement rates for dental care delivered to Medicaid eligible patients has
Correspondence: Beau Meyer

Department of Pediatric Dentistry,

School of Dentistry, University of North

Carolina - Chapel Hill, 228

Brauer Hall, Campus Box \#7450,

Chapel Hill, NC 27599, USA

Tel + I 9195373814

Fax + I 9195373950

Email beau_meyer@unc.edu
Clinical, Cosmetic and Investigational Dentistry 2016:8 5I-56

(c) (1) (8) ๑ 2016 Meyer et al. This work is published and licensed by Dove Medical Press Limited. The full terms of this license are available at https://wwr.doverpes.com/terms. cc) you herbby accept the Terms. Non-commercial uses of the work are permitted without any further permision from Dove Medical Press Limited, provided the work is properly attributed. For permision for commercial use of this work, please see paragraphs 4.2 and 5 of our Terms (hthps.//www.dovepreses.com/terms.php).
Dovepress

http://dx.doi.org/10.2147/CCIDE.S101195 
decreased in many states, and subsequently, there has been a concomitant reduction in the number of participating Medicaid providers. ${ }^{11}$ Accordingly, hospital ED visits for dental reasons continue to be a problem.

Some EDs have successfully referred patients directly from the ED to an adjacent emergency dental clinic (EDC), reducing the number of dental-related ED visits the following year by $52 \%$ and the number of repeat visitors by $66 \%{ }^{12}$ The inspiration for the present investigation was a response to an area hospital council's desire to divert high numbers of ED dental patients to a more appropriate source of care.

The objective of this investigation was to obtain a more thorough characterization of the patients using EDs for dental care. Specifically, this study aimed to determine the follow-up rate to an EDC after a dental-related ED visit, according to a recently implemented referral process.

\section{Materials and methods}

A referral process was recently put into place as a standard of care from the university-based ED to the low-cost, universitybased EDC. The university-based ED was selected because of its proximity to the EDC. The EDC operates within the university's dental school which is adjacent to the university hospital. The EDC is a walk-in clinic and provides limited care to address emergent or urgent dental problems. In some cases, it serves as a referral source for comprehensive patient care at the dental school.

The referral process provides verbal instructions and a discharge pamphlet to all adult ED patients with a nontraumatic dental visit, whose chief complaint is dental pain or facial swelling. Treatment in the ED consists of prescription analgesics with or without an antibiotic, based on the clinical impressions of the treating physician. Instructions in the pamphlet explain how the patient can receive follow-up dental care at the EDC as well as a cost estimate for services required to address the ED-driven complaint. ED dental patients are given priority status as walk-in patients at the EDC, and next business day treatment is guaranteed as part of the referral. However, patients are expected to pay for the service or their insurance copayment. Additionally, data including name, age, ethnicity, sex, telephone number, and date of ED visit are faxed to the EDC upon discharge, as part of the standard referral.

On the EDC end of the referral, patients are followed to see who does and does not follow-up at the EDC within 24 hours of referral from the ED. For patients who do not follow-up within 24 hours, a telephone call is made by a trained EDC staff member following a standard script. The patients are reminded of the walk-in nature of the EDC and their priority status as an ED referral, as well as provided an opportunity to schedule an appointment if desired. If there is no response to the initial call, additional calls are made at days 3 and 7 following the referral date. If no response is obtained after three attempts, no further contact is attempted.

This prospective study tracked patients referred under this new referral process over a 6-month period (from June to December 2014). Inclusion criteria included all adults 18 years or older, who were referred to the EDC after seeking care for nontraumatic dental reasons at the hospital ED. A key assumption of the referral is that nontraumatic dental visits to a hospital ED involve some degree of dental pain. All study procedures were approved by the Ohio State University's Institutional Review Board. For the purpose of this study, consent was not obtained in the ED in order to minimize the influence on follow-up, since the primary interest was determining the number of patients who follow-up at the EDC on a nontraumatic dental complaint when provided an opportunity to do so.

Select investigators (BM and FGR) monitored the utilization of the EDC by those referred from the ED over the 6-month study period. These referrals were monitored for subsequent use of the university's comprehensive care dental clinics to determine whether or not patients presenting from the ED would seek to establish the university dental clinic as his/her regular source of dental care.

The study outcomes included the number of dental-related ED visits, the number of referred patients who followed up at the EDC for definitive treatment, the number of patients unable to be reached, and the referral patterns of ED presentation by day of the week and time of day.

Study data were collected using the web-based application REDCap (Research Electronic Data Capture), which allows electronic data collection and management. ${ }^{13}$ Descriptive statistics were reported for the sample characteristics using R statistics software version 3.1.3 (R Foundation for Statistical Computing, Vienna, Austria). ${ }^{14}$ Chi-squared analyses were used to determine demographic differences between the two referral sources.

\section{Results}

Over the 6-month study period, 247 referrals were made from the ED to the EDC. A total of 77 patients (31\%) followed up for treatment at the EDC, when provided an opportunity to do so. Telephone contact could not be made with $75 \%$ of those who did not follow-up at the EDC (128/170). For those who could be reached by phone, $17 \%$ (7/42) stated they did not follow-up because they could not pay for services and $5 \%(2 / 42)$ confirmed that they sought treatment at a different dental facility. 
Significantly more patients visited the ED on weekends and Mondays as compared to the rest of the week $(P<0.001)$ (Figure 1); however, this difference did not influence whether or not the patient followed up at the $\operatorname{EDC}(P=0.475)$.

\section{ED dental patients}

Caucasians and African-Americans comprised $80 \%$ of the patient base presenting to the ED with a nontraumatic dentalrelated complaint (Table 1). The population presenting to the ED is generally young, with $20-39$ year olds accounting for $68 \%$ of the patients. There was no sex predilection. Almost $70 \%$ of the patients had some form of dental insurance.

\section{Follow-up care at EDC}

The mean time elapsed from referral to follow-up at the EDC was 1.7 days (standard deviation $=2.1$ ). Caucasians and African-Americans accounted for $84 \%$ of the referrals who followed up for definitive care at the EDC. Two-thirds of the follow-ups were from those aged between 20 and 39, and just over half of them were male (Table 1). While 77 presented for follow-up care, only 70 completed the visit with treatment rendered. The remaining seven preferred not to receive treatment due to costs or extended wait times.

Total care billed in the EDC was $\$ 11,415$, which excluded one bill totaling more than $\$ 3,000$ for the placement of extraoral drains in three separate anatomic spaces. The average cost per EDC visit was $\$ 163.07$, and the most commonly billed procedures were examinations $(n=74)$, extractions $(\mathrm{n}=51$ simple, 15 surgical), incision and drainage $(\mathrm{n}=13)$, and pulpal debridement $(\mathrm{n}=10)$. These 70 patients averaged 2.7 total visits (range: $0-10$ ) to the university's comprehensive dental clinic after being treated in the EDC. Of the 77 who followed up, eleven established the university dental clinics as his or her dental home (14\%).

\section{Discussion}

The Dental Quality Alliance has proposed measures to assess the quality of dental care, and one of these is follow-up after an emergency dental visit. ${ }^{15}$ The present study suggests that this particular quality measure may suffer when the population using an ED for nontraumatic dental reasons cannot be contacted to encourage or ensure follow-up after the ED visit. In general, it seems difficult to find ways to include dental treatments into accountable care organizations (ACO) where payments to providers are reflected by the quality measures they achieve. However, some organizations - in Iowa, Minnesota, Ohio, California, and Oregon - have found a way to make it work, and applying the ACO model of care delivery for dentistry in other states bears consideration moving forward. ${ }^{16}$

The most significant finding of this study was the EDC's inability to contact ED referral patients who did not seek follow-up care at the EDC. Of those who did not follow-up, $75 \%$ could not be contacted via telephone in three attempts. Considering that the existing referral process was designed to divert ED dental patients to a more appropriate source of care, the inability to contact the referred patients poses a significant challenge to its effectiveness.

Improvement upon the low follow-up rate to the EDC (31\%) in the present study may be achieved in several ways. Logistically speaking, one solution based on these findings might be to ask ED patients how they prefer to be contacted

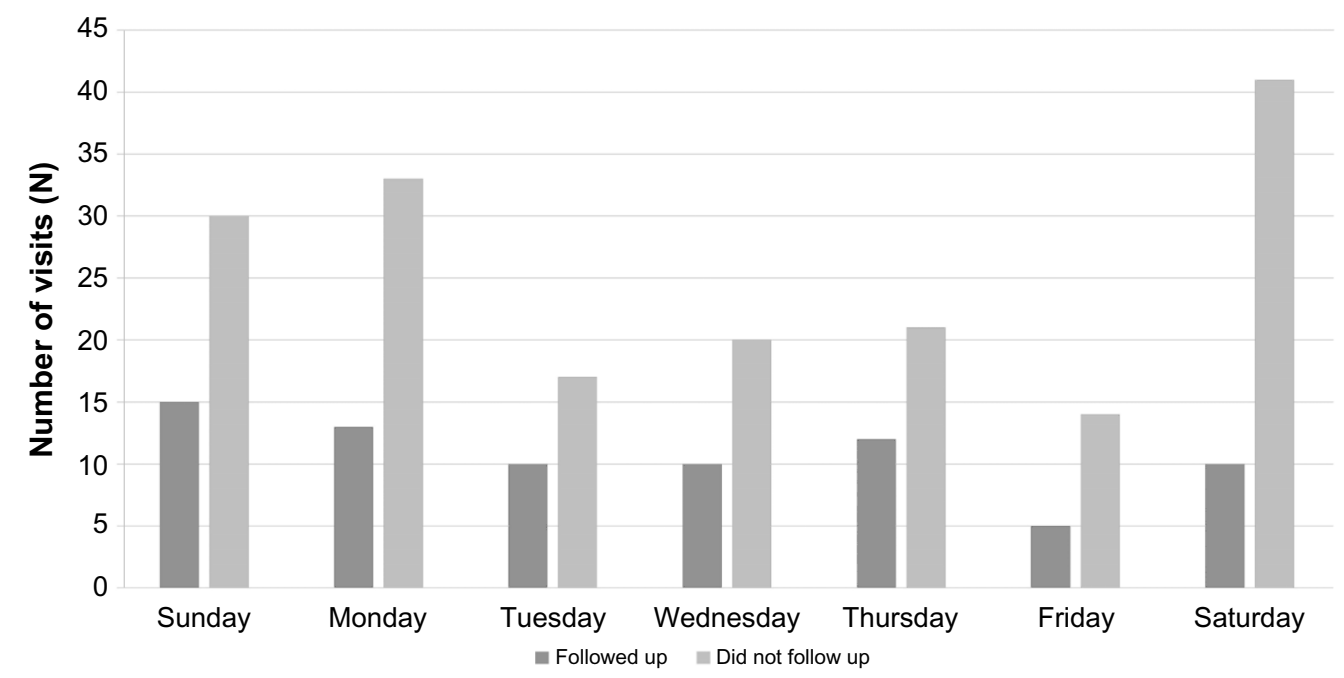

Figure I Frequency distribution showing the day of the week in which patients used the hospital emergency department grouped by follow-up status to the emergency dental clinic. 
Table I Summary of demographic information for hospital ED dental patients and those who followed up at the EDC

\begin{tabular}{|c|c|c|c|c|c|}
\hline \multicolumn{2}{|c|}{ ED dental patients } & \multirow{2}{*}{$\begin{array}{l}\mathbf{N}=\mathbf{2 4 7}(\%) \\
116(47)\end{array}$} & \multicolumn{2}{|c|}{ Follow-up at EDC } & \multirow{2}{*}{$\begin{array}{l}\mathbf{N}=\mathbf{7 7}(\%) \\
40(5 \mathrm{I})\end{array}$} \\
\hline Race & Caucasian & & Race & Caucasian & \\
\hline & African-American & $80(33)$ & & African-American & $26(33)$ \\
\hline & Other & $47(19)$ & & Other & $9(12)$ \\
\hline & Native American & $2(1)$ & & Native American & $I(I)$ \\
\hline & Hispanic & $2(1)$ & & Hispanic & $I(I)$ \\
\hline \multirow[t]{7}{*}{ Age, years } & $<20$ & $10(4)$ & Age, years & $<20$ & $I(I)$ \\
\hline & $20-29$ & $104(42)$ & & $20-29$ & $31(40)$ \\
\hline & $30-39$ & $65(26)$ & & $30-39$ & $19(24)$ \\
\hline & $40-49$ & $44(18)$ & & $40-49$ & $13(17)$ \\
\hline & $50-59$ & $19(8)$ & & $50-59$ & $9(12)$ \\
\hline & $60-69$ & $2(1)$ & & $60-69$ & $2(3)$ \\
\hline & $>70$ & $3(1)$ & & $>70$ & $2(3)$ \\
\hline \multirow[t]{2}{*}{ Sex } & Male & $|2|(49)$ & Sex & Male & $43(55)$ \\
\hline & Female & $126(5 \mid)$ & & Female & $34(44)$ \\
\hline \multirow[t]{2}{*}{ Insurance } & Yes & $170(69)$ & Insurance & Yes & $4 \mid(53)$ \\
\hline & No & $77(3 \mathrm{I})$ & & No & $36(46)$ \\
\hline
\end{tabular}

Abbreviations: ED, emergency department; EDC, emergency dental clinic.

during the ED registration process and to verify that method of contact prior to each patient's discharge from the ED. It seems this would at least provide the possibility to improve the likelihood of contacting the patient following an ED visit.

Another method to improve the referral protocol described in this study would be to address the time of presentation at the ED. Many patients were seen on the weekends at the EDs, which is consistent with the findings of Okunseri et al. ${ }^{17}$ If hospital EDs continue to experience regular dental visits, it may be most beneficial and pragmatic for EDs to provide dental extractions performed in coordination with a licensed dentist. Local dental societies could create on-call groups in suburban or urban areas to facilitate this provision of care, creating a cohort of dentists accessible to ED staff as they work to identify follow-up care options for patients with dental complaints. These ED visits also represent a meaningful application of dental case managers or the American Dental Association's new Community Dental Health Coordinator. While these Community Dental Health Coordinators focus on prevention and education efforts, there is a component of case management and care coordination which would make them a useful tool in resolving ED dental visits and follow-up. ${ }^{18}$

As the current investigation demonstrates, a single referral is likely not enough to address the issue of inappropriate use of the ED for dental reasons. Recently, the American Dental Association's Health Policy Institute published a policy brief that advocated for ED dental diversion programs that are similar to a program described by McCormick et al. ${ }^{12,19}$ In that program, patients were diverted from the ED to an adjacent EDC immediately following triage. ${ }^{12}$ This arrangement of an ED adjacent to an EDC was likely a major reason for its success. Applying this setup to different locations might be difficult due to space and financial limitations involved in establishing EDCs adjacent to EDs.

Based on previous reports, it was not surprising that nearly $60 \%$ of those using the ED had public insurance. ${ }^{1-5}$ The Medicaid program in the State of Ohio covers a broad scope of preventive, surgical, and restorative adult dental services. One way to improve treatment utilization by those in need may be to create a staff position at the ED that is dedicated to explaining insurance and benefits at patient registration. The liaison could help determine Medicaid eligibility, explain the benefits, and assist the patient with the insurance application process if he/she is eligible. This position could be likened to the "navigators" used to help the US citizens sign up for insurance through the federal marketplace. ${ }^{20}$ It seems reasonable to assume that patients who qualify for and obtain public insurance, particularly the young adults, ${ }^{3}$ may be more receptive to utilizing preventive dental care services than those without such coverage. However, it remains to be seen how Medicaid expansion will influence the provision of dental care in EDs. In fact, a recent review suggests that providing dental insurance alone via Medicaid expansion might not be enough to reduce dental visits to EDs. ${ }^{21}$

Beyond the suggestions listed previously, the cost of emergency dental services requires some consideration. Only $16 \%$ of those who did not follow-up and could be contacted stated that cost was the reason they could not 
follow-up. While there is no way to definitively discern why the unreachable population did not follow-up at the EDC, cost could certainly have been an issue. If the ACO model is applied to include dentistry, perhaps the cost issue becomes even less of a factor influencing ED use for dental reasons.

\section{Limitations}

This study had significant limitations affecting the generalization of its findings to other populations. First, the study was limited to a university-based system in an urban setting, and the findings may not apply to other urban settings or rural community EDs. Second, this study only looked at the follow-up rate of an existing referral process, not the reasons behind failed referrals. A more robust study design would allow an examination of factors that might predict successful referrals, as well as reasons for ED use in the first place. Furthermore, interventional studies could be designed to ensure follow-up care on the chief dental complaint.

This study also attempted to elicit barriers to care, but results of the survey were deemed nonrobust based on both a $17 \%$ survey response rate and a population that was unable to be contacted by telephone (75\%). The survey was intended to reach out to this population; however, they proved unreachable, and the quality of the survey data is too poor to report.

\section{Conclusion}

Less than one-third of the ED referrals to the EDC followed up for definitive care and $75 \%$ of the referrals could not be contacted. Ensuring appropriate dental follow-up from the ED and diverting the dental complaints to established dental clinics are difficult and complex. Coordination between dental clinics and EDs is an essential component for developing better ED diversion programs for dental patients. The ACO insurance models deserve consideration when contemplating solutions to the ED dental visit problem. Future research to examine care coordination is needed to both improve patient care and reduce the dental impact on EDs. The problem is clearly complex, yet the solutions are decidedly murky.

\section{Acknowledgments}

The investigation was partially supported by the Ohio State University Wexner Medical Center, Ohio. Data collection and analysis was supported by the Ohio State University Center for Clinical and Translational Science (National Center for Advancing Translational Sciences, Grant UL1TR001070).
The authors would like to acknowledge Patrick Lloyd, DDS, MS, William Vann, DMD, PhD, and Jessica Lee DDS, MPH, $\mathrm{PhD}$ for their editorial critiques of the manuscript.

\section{Disclosure}

The authors report no conflicts of interest in this work.

\section{References}

1. Seu K, Hall KK, Moy E. Emergency department visits for dental-related conditions, 2009: Statistical Brief\#143. Healthcare Cost and Utilization Project (HCUP) Statistical Briefs [Internet]. Rockville, MD: Agency for Health Care Policy and Research; 2012. Available from: http://www. ncbi.nlm.nih.gov/books/NBK116745/. Accessed April 26, 2015.

2. Anderson L, Cherala S, Traore E, Martin NR. Utilization of hospital emergency departments for non-traumatic dental care in New Hampshire, 2001-2008. J Community Health. 2011;36:513-516.

3. Lewis CW, McKinney CM, Lee HH, Melbye ML, Rue TC. Visits to US emergency departments by 20 - to 29 -year-olds with toothache during 2001-2010. J Am Dent Assoc. 2015;146:295-302.e2.

4. Allareddy V, Rampa S, Lee MK, Allareddy V, Nalliah RP. Hospital-based emergency department visits involving dental conditions: profile and predictors of poor outcomes and resource utilization. JAm Dent Assoc. 2014;145:331-337.

5. Walker A, Probst JC, Martin AB, Bellinger JD, Merchant A. Analysis of hospital-based emergency department visits for dental caries in the United States in 2008. J Public Health Dent. 2014;74:188-194.

6. U.S. Department of Health and Human Services. Oral Health in America: A Report of the Surgeon General. Rockville, MD: U.S. Department of Health and Human Services, National Institute of Dental and Craniofacial Research, National Institutes of Health; 2000.

7. Cohen LA, Manski RJ. Visits to non-dentist health care providers for dental problems. Fam Med. 2006;38:556-564

8. Davis EE, Deinard AS, Maiga EW. Doctor, my tooth hurts: the costs of incomplete dental care in the emergency room. J Public Health Dent. 2010;70:205-210.

9. Wall T, Vujicic M. Emergency department use for dental conditions continues to increase. Health Policy Institute Research Brief [Internet] Chicago, IL: American Dental Association; April 2015. Available from: http://www.ada.org/ /media/ADA/Science\%20and\%20Research/HPI/ Files/HPIBrief_0415_2.ashx. Accessed September 15, 2015.

10. Nasseh K, Vujicic M. Dental benefits continue to expand for children, remain stable for working-age adults. Health Policy Institute Research Brief [Internet]. Chicago, IL: American Dental Association; October 2013. Available from: http://www.ada.org/sections/professionalResources/pdfs/HPRCBrief_1013_3.pdf. Accessed September 14, 2015.

11. Nasseh K, Vujicic M, Yarbrough C. A ten-year, state-by-state, analysis of Medicaid fee-for-service reimbursement rates for dental care services. Health Policy Institute Research Brief [Internet]. Chicago, IL: American Dental Association; October 2014. Available from: http:// www.ada.org/ /media/ADA/Science\%20and\%20Research/HPI/Files/ HPIBrief_1014_3.ashx. Accessed September 15, 2015.

12. McCormick AP, Abubaker AO, Laskin DM, Gonzales MS, Garland S. Reducing the burden of dental patients on the busy hospital emergency department. J Oral Maxillofac Surg. 2013;71:475-478.

13. Harris PA, Taylor R, Thielke R, Payne J, Gonzalez N, Conde JG Research electronic data capture (REDCap) - A metadata-driven methodology and workflow process for providing translational research informatics support. J Biomed Inform. 2009;42:377-381.

14. R Core Team. R: A Language and Environment for Statistical Computing [Internet]. Vienna, Austria: R Foundation for Statistical Computing; 2013. Available from: http://www.R-project.org/. Accessed January 10, 2015. 
15. Dental Quality Alliance. Proposed Adult Measures. Dental Quality Alliance [Internet]. Chicago, IL: American Dental Association; 2014. Available from: http://www.ada.org/ /media/ADA/Science $\% 20$ and $\% 20$ Research/Files/Adult_Measures_under_consideration.ashx. Accessed September 15, 2015.

16. Leavitt Partners. Dental Care in Accountable Care Organizations: Insights from 5 Case Studies. Chicago, IL: ADA Health Policy Institute and AAPD Pediatric Oral Health Policy Center; June 2015.

17. Okunseri C, Okunseri E, Fischer MC, Sadeghi SN, Xiang Q, Szabo A. Nontraumatic dental condition-related visits to emergency departments on weekdays, weekends and night hours: findings from the National Hospital Ambulatory Medical Care survey. Clin Cosmet Investig Dent. 2013;5:69-76.

18. Calnon WR, Faiella RA, Blanton PL, et al. Breaking down barriers to oral health for all Americans: The community dental health coordinator. Chicago, IL: American Dental Association; October 2012.
19. Wall T, Nasseh K, Vujicic M. Majority of dental-related emergency department visits lack urgency and can be diverted to dental offices. Health Policy Institute Research Brief [Internet]. Chicago, IL: American Dental Association; August 2014. Available from: http:// www.ada.org/ /media/ADA/Science\%20and\%20Research/HPI/Files/ HPIBrief_0814_1.ashx. Accessed November 20, 2015.

20. Centers for Medicare and Medicaid Services. Ways to help consumers apply and enroll in health coverage through the marketplace. CMS [Internet]. Baltimore, MD: US Department of Health and Human Services; 2014. Available from: https://www.cms.gov/CCIIO/Resources/ Fact-Sheets-and-FAQs/Downloads/AssistanceRoles_06-10-14-508.pdf. Accessed November 20, 2015.

21. Fingar KR, Smith MW, Davies S, McDonald KM, Stocks C, Raven MC. Medicaid dental coverage alone may not lower rates of dental emergency department visits. Health Affairs. 2015;34:1349-1357.

\section{Publish your work in this journal}

Clinical, Cosmetic and Investigational Dentistry is an international, peer-reviewed, open access, online journal focusing on the latest clinical and experimental research in dentistry with specific emphasis on cosmetic interventions. Innovative developments in dental materials, techniques and devices that improve outcomes and patient satisfac- tion and preference will be highlighted. The manuscript management system is completely online and includes a very quick and fair peerreview system, which is all easy to use. Visit http://www.dovepress. com/testimonials.php to read real quotes from published authors.

Submit your manuscript here: http://www.dovepress.com/clinical-cosmetic-and-investigational-dentistry-journal 